\title{
DynamicSainT
}

Jilid. V No. 1., April 2020

\section{PENINGKATAN EFFISIENSI KERJA MOTOR INDUKSI 3 PHASA ( PENGUJIAN KARAKTERISTIK MOTOR INDUKSI 3 PHASA )}

\author{
Yusri Ambabunga \\ Program Studi Teknik Elektro, Fakultas Teknik, Universitas Kristen Indonesia Toraja. \\ Jl. Nusantara No. 12,Makale, Tana Toraja, Sulawesi Selatan \\ yusriambabunga@ukitoraja.ac.id
}

\begin{abstract}
ABSTRAK
Penelitian ini bertujuan memecahkan masalah yang terkait dengan motor induksi 3 phasa yaitu, pertama, menunjukkan pengaruh jenis pengasutan motor yang digunakan khususnya sistem DOL dan bintang segitiga terhadap arus starting yang dihasilkannya dan putaran motor; kedua, menentukan setting timer pada pengasutan bintang segitiga pada motor induksi 3 phasa;dan yang ketiga, menampilkan bentuk gelombang arus yang dihasilkan pada pengasutan DOL dan bintang segitiga pada motor induksi 3 phasa, serta bagaimana menampilkan bentuk gelombang tegangan dan putaran rotor motor induksi pada saat kondisi beban nol dan pada saat kondisi beban penuh (steady state) yang mempengaruhi karakteristik kerja motor induksi 3 phasa pada sistem jaringan instalasi listrik 3 phasa pada sistem tenaga listrik.
\end{abstract}

Kata Kunci: Motor Induksi 3 Phasa, Contactor, Relay proteksi arus dan tegangan, MCB, CT dan VT.

\section{PENDAHULUAN}

Kemajuan teknologi sekarang ini sangat memungkinkan peningkatan kualitas produksi secara maksimal. Hampir semua proses produksi pada industri-industri maju menggunakan motor listrik. Hal ini akan berdampak terhadap ketersediaan energi khususnya energi listrik.

Motor listrik khususnya motor induksi memerlukan suatu penanganan khusus. Terutama dalam pengelolaan daya yang akan dikonsumsi saat beroperasi. Hal ini dimaksudkan agar proses industri dapat tetap berjalan meskipun energi yang tersedia terbatas.

Salah satu bagian motor induksi yang membutuhkan banyak energi atau daya adalah saat start awal. Pada saat diasut dan sebelum motor mulai berputar, tidak ada GGL lawan yang membatasi arus dan awalnya ada arus eksitasi. Karena arus tersebut terjadi sebelum rotor bergerak, arus rotor yang ditahan akan sama, saat motor sedang diasut tanpa beban maupun dalam keadaan beban penuh. Arus rotor ditahan dapat mencapai enam kali arus kerja normal.

Makin tinggi effisiensi kerja motor makin tinggi arus start dan arus beban. Pada motor induksi jangkar hubung singkat diatas sekitar $2 \mathrm{~kW}$ dapat menghasilkan gangguan tetap sumber listrik. Alat pengasut bintang segitiga mengurangi arus asut sampai sekitar dua kali arus beban penuh. Akan tetapi, perlu setting timer yang tepat untuk perpindahan dari hubungan bintang ke segitiga. Jika setting timer terlalu cepat, arus eksitasi akan besar yang dapat merusak belitan motor. Sebaliknya, setting timer yang terlalu lama meskipun arus eksitasinya tidak terlalu besar tetapi dengan waktu yang lama, putaran nominal lambat dicapai.

Berdasarkan fakta di atas maka diperlukan suatu setting timer yang tepat. Hal ini dimaksudkan agar arus tidak terlalu besar pada start awal dan putaran nominal dapat tercapai. Untuk menentukan setting timer yang tepat serta pengaruhnya terhadap konsumsi daya yang dihasilkan maka dirancanglah alat ukur karakteristik arus dan 


\section{DynamicSainT}

Jilid. V No. 1., April 2020

putaran motor.

Alat ini mampu menampilkan grafik arus dan putaran. Dengan demikian analisa arus starting dan putaran nominal motor dapat dilakukan.

\section{METODOLOGI}

Metode penelitian yang dilakukan disini adalah dengan menggunakan metode pendekatan simulasi rangkaian system 3 phasa dengan menggunakan software Matlab, dimana data mentah yang diperoleh dari hasil pengamatan lalu data tersebut dimasukkan ke dalam software matlab baik data pada saat beban nol dan data pada saat kondisi motor induksi 3 phasa dibebani penuh sehingga dihasilkan data olahan yang sudah melalui proses Run pada software tersebut sehingga selain data olahan yang didapatkan juga gambar grafik simulasi terkait arus pengasutan, arus listrik beban penuh, kecepatan putaran motor induksi 3 phasa serta tegangan listrik kondisi beban nol pada saat pengasutuan dan kondisi motor induksi 3 phasa pada beban penuh (full load). Pelaksaanan uji simulasi tentang template pada motor induksi 3 phasa dilakukan pada laboratorium listrik tegangan tinggi dan dilengkapi dengan sejumlah perangkat computer dan fasilitasnya untuk mendukung uji simulasi rangkaian motor induksi 3 phasa sehingga di dapatkan gambaran secara grafik tentang karakteristik kerja motor induksi 3 phasa AC.

\section{HASIL DAN PEMBAHASAN}

Motor arus bolak balik (AC) diklasifikasikan dengan dasar prinsip pengoperasian sebagai motor induksi atau asinkron. Perputaran motor AC ditimbulkan oleh adanya medan putar (fluks yang berputar) yang dihasilkan dalam kumparan statornya. Motor induksi dapat dibuat baik untuk jenis tiga-fasa maupun satu-fasa, karena motor induksi tidak ada tegangan eksternal yang diberikan pada rotornya.

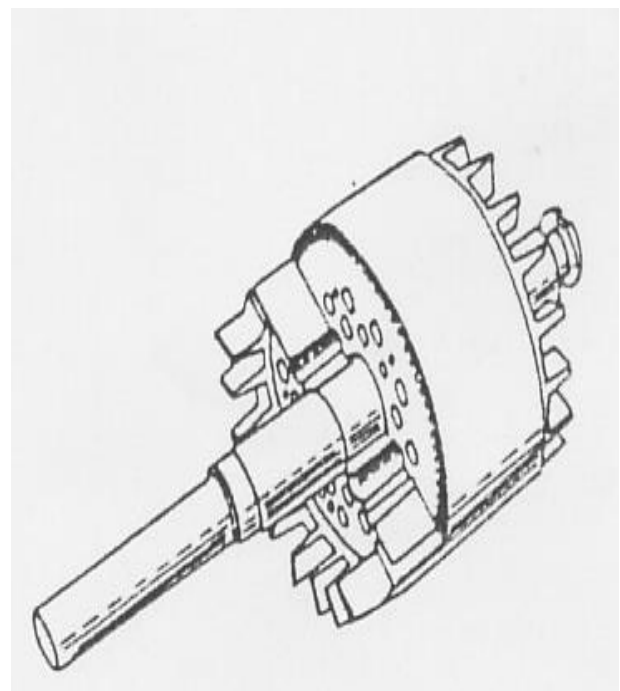

Gambar 1. Rotor sangkar

Keistimewaan umum dari motor ac adalah medan magnet putar yang diatur dengan lilitan stator. Konsep ini dapat diilustrasikan pada motor tiga-fasa dengan mempertimbangkan tiga kumparan yang diletakkan bergeser $120^{\circ}$ listrik satu sama lain. Masing-masing kumparan dihubungkan dengan satu-fasa sumber daya tiga-fasa. Apabila arus tiga-fasa melewati lilitan tersebut, terjadi pengaruh medan magnet berputar tergantung pada jumlah kutub stator. Kecepatan medan magnet putar tergantung pada jumlah kutub stator dan frekuensi sumberdaya.

Prinsip kerja motor induksi dapat dijelaskan sebagai berikut :

1) Apabila sumber tegangan tiga fasa dihubungkan pada kumparan stator maka akan timbul suatu medan putar dengan kecepatan sinkron (ns). Dimana :

$$
N s=\frac{120 f}{P}
$$

Dimana :

Ns $=$ Kecepatan sinkron (rpm)

$\mathrm{f}=$ Frekuensi sumberdaya $(\mathrm{Hz})$

$\mathrm{P}=$ Jumlah lilitan kutub pada tiap lilitan satu fasa

2) Medan putar stator tersebut akan memotong batang-batang konduktor pada rotor. 


\section{DynamicSainT}

Jilid. V No. 1., April 2020

3) Akibatnya pada kumparan rotor timbul dengan induksi ggl sebesar

$$
\mathrm{E}_{2 \mathrm{~s}}=4,44 \mathrm{f}_{2} \mathrm{~N}_{2} \Phi \mathrm{m}
$$

4) Karena kumparan rotor merupakan rangkaian tertutup, ggl (E) akan menghasilkan arus.

5) Adanya arus didalam medan magnet menimbulkan gaya (F) pada rotor.

6) Bila kopel mula yang dihasilkan oleh gaya (F) pada rotor cukup besar untuk memikul kopel beban, rotor akan berputar searah dengan medan putar stator.

7) Tegangan induksi timbul karena terpotongnya batang konduktor (rotor) oleh medan putar stator $\left(\mathrm{n}_{\mathrm{s}}\right)$. Agar tegangan terinduksi diperlukan adanya perbedaan relatif antara kecepatan medan putar stator dengan kecepatan berputar rotor $\left(n_{\mathrm{r}}\right)$.

8) Perbedaan kecepatan antara $\mathrm{nr}$ dan $\mathrm{ns}$ disebut slip (S) dinyatakan dengan :

$$
S=\frac{n_{s}-\mathrm{n}_{\mathrm{r}}}{n_{s}} \times 100 \%
$$

9) Bila $n_{r}=n_{s}$, tegangan tidak akan terinduksi dan arus tidak akan mengalir pada kumparan jangkar rotor dengan demikian tidak dihasilkan kopel. Kopel motor akan ditimbulkan apabila $\mathrm{n}_{\mathrm{s}}<\mathrm{n}_{\mathrm{s}}$.

Berubah-ubahnya kecepatan motor induksi $\left(\mathrm{n}_{\mathrm{r}}\right)$ mengakibatkan berubahnya harga slip $(\mathrm{S})$ dari $100 \%$ pada saat start sampai $0 \%$ pada saat motor diam $\left(\mathrm{n}_{\mathrm{s}}=\mathrm{n}_{\mathrm{r}}\right)$. Dalam keadaan berputar frekuensi arus motor dipengaruhi arus slip $\left(\mathrm{f}_{2}\right.$ $\left.=S . f_{1}\right)$. Karena tegangan induksi dan reaktansi kumparan rotor merupakan fungsi frekuensi, maka dengan demikian harganya ikut berubah-ubah karena perubahan slip.

Pengujian motor induksi dilakukan dengan menggunakan start dari komputer. Dimana pada proyek akhir ini dilakukan dengan cara :

- Pengujian dengan sistem Direct On Line (DOL starter);

- Pengujian dengan sistem pengasutan bintang - segitiga (Y- $\Delta$ ).
Adapun spesifikasi motor induksi yang digunakan adalah :

$\begin{array}{ll}\text { Phasa } & : 3 \Phi \\ \text { Daya } & : 1,5 \mathrm{Kw} \\ \text { Tegangan } & : Y 380 / \Delta 660 \mathrm{~V} \\ \text { Putaran } & : 1500 \mathrm{rpm}\end{array}$

\subsection{Pengujian dengan sistem Direct On Line (DOL)}

Pengujian motor disini dilakukan dengan cara menghubungkan secara langsung motor induksi dengan sumber 3 phasa. Hubungan yang digunakan adalah hubungan segitiga (Delta). Gambar dari pengujian ini dapat dilihat pada gambar 2. berikut :

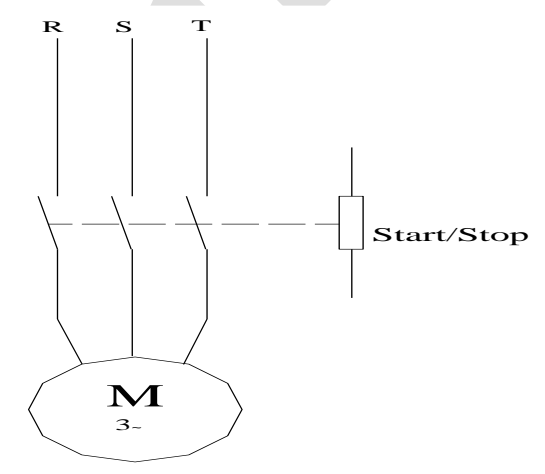

Gambar 2 . Rangkaian sistem DOL

Adapun cara kerja dari rangkaian tersebut adalah pada saat tombol start di on kan maka kontaktor akan bekerja dan motor akan mendapatkan tegangan suplai 380 volt.

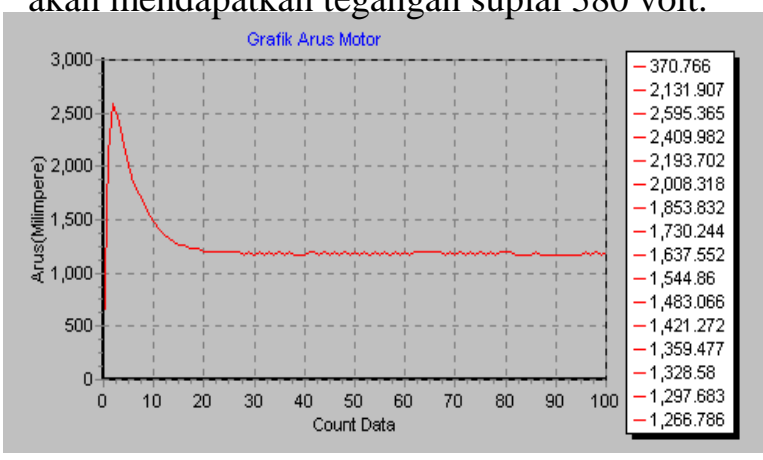

Gambar 3. Karakteristik arus start sistem DOL

Besarnya arus start yang timbul dapat dijelaskan dari gambar 3. rangkaian ekivalen motor induksi. Dari gambar ekivalen motor tersebut dapat dijelaskan bahwa pada sistem DOL apabila tegangan dimasukkan saat 


\section{DynamicSainT}

Jilid. V No. 1., April 2020

motor belum berputar, harga dari slip $(\mathrm{S})=1$. Nilai R2/S akan bernilai kecil sehingga arus yang mengalir sangat besar. Pada saat motor telah berputar, slip akan berkurang mendekati nol dan tahanan rotor $\mathrm{R} 2 / \mathrm{S}$ akan naik dan arus motor akan turun.

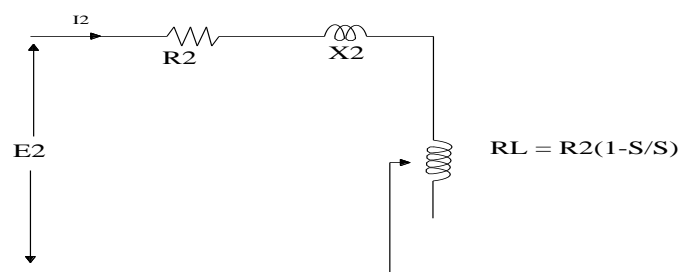

Gambar 4. Rangkaian ekivalen motor induksi

\subsection{Pengujian dengan sistem pengasutan bintang-segitiga (Y- $\Delta$ ) \\ Untuk pengujian starting $\mathrm{Y}-\Delta$} mempunyai bentuk rangkaian seperti gambar 4.5. Cara kerja dari starting $\mathrm{Y}-\Delta$ adalah saat tombol start ditekan maka main kontaktor dan kontaktor Y akan bekerja sehingga kumparan motor akan terhubung Y. Beberapa saat kemudian kontaktor $\Delta$ bekerja disaat yang sama kontaktor Y off. Adapun karakteristik arus starting dapat dilihat pada gambar rangkaian 5 .
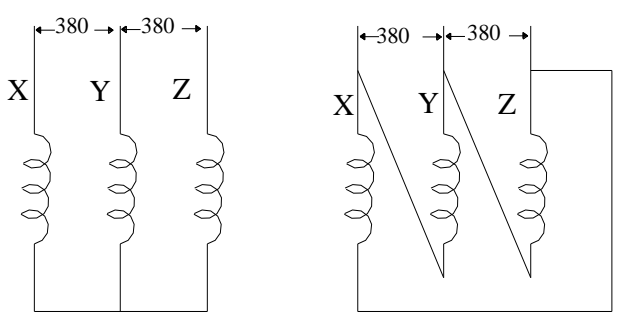

Gambar 5. Hubungan motor dengan STARTING $Y-\Delta$

\section{a. Analisis arus}

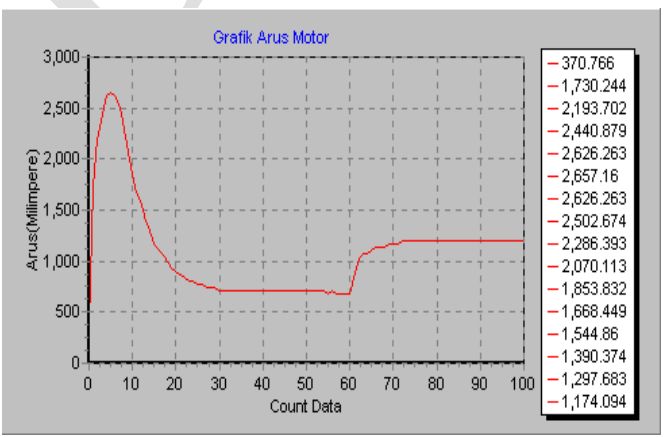

Gambar 6. Karakteristik arus start dengan start $Y-\Delta$
Saat hubungan bintang (Y) masingmasing line menyuplai dua belitan phasa. Dengan demikian nilai resistansi lebih besar sehingga arus menjadi kecil. Sedangkan pada hubungan delta $(\Delta)$ masing-masing line hanya menyuplai satu kumparan phasa. Dengan demikian nilai resistansi lebih kecil.

\section{b. Analisis putaran}

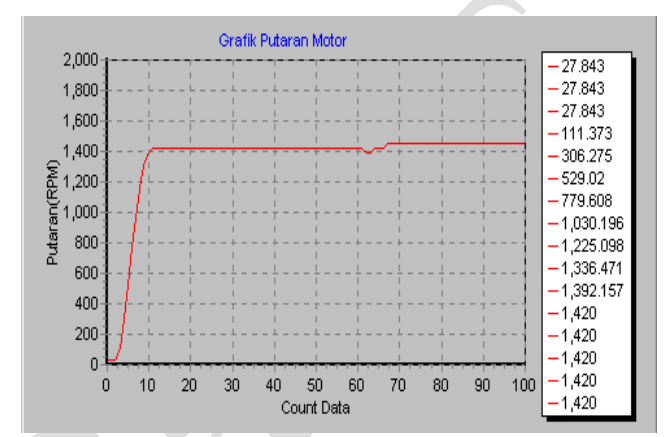

Gambar 7. Karakteristik putaran motor pada hubungan $Y-\Delta$

Perbedaan arus pada saat motor terhubung secara bintang $(\mathrm{Y})$ dengan arus saat hubung delta $(\Delta)$ mempengaruhi karakteristik putaran motor. Perubahan arus sebanding dengan perubahan fluks. Perubahan fluks tersebut akan mempengaruhi tegangan yang diinduksikan pada rotor. Dengan demikian, putaran rotor akan berubah tergantung dari besarnya tegangan yang diinduksikan.

Saat hubung bintang (Y), arus yang mengalir lebih kecil dibandingkan arus saat hubungan delta $(\Delta)$. Hal ini berarti tegangan yang diinduksikan pun saat hubungan $\mathrm{Y}$ lebih kecil dibandingkan dengan saat hubungan delta. Dengan demikian, putaran pada Y lebih rendah daripada hubungan delta.

\section{c. Penentuan setting timer}

Untuk menentukan nilai setting timer yang tepat dilakukan dengan melihat karakteristik arus starting motor dan putarannya. Jika perpindahan dari hubungan bintang $(\mathrm{Y})$ ke hubungan segitiga $(\Delta)$ terjadi sebelum arus puncak terjadi maka arus starting akan menjadi besar.

Dalam penentuan nilai setting timer pada 


\section{DynamicSainT}

Jilid. V No. 1., April 2020

motor yang digunakan ini, dilakukan dengan memperhatikan karakteristik arus dan putaran yang ditampilkan dalam bentuk grafik.

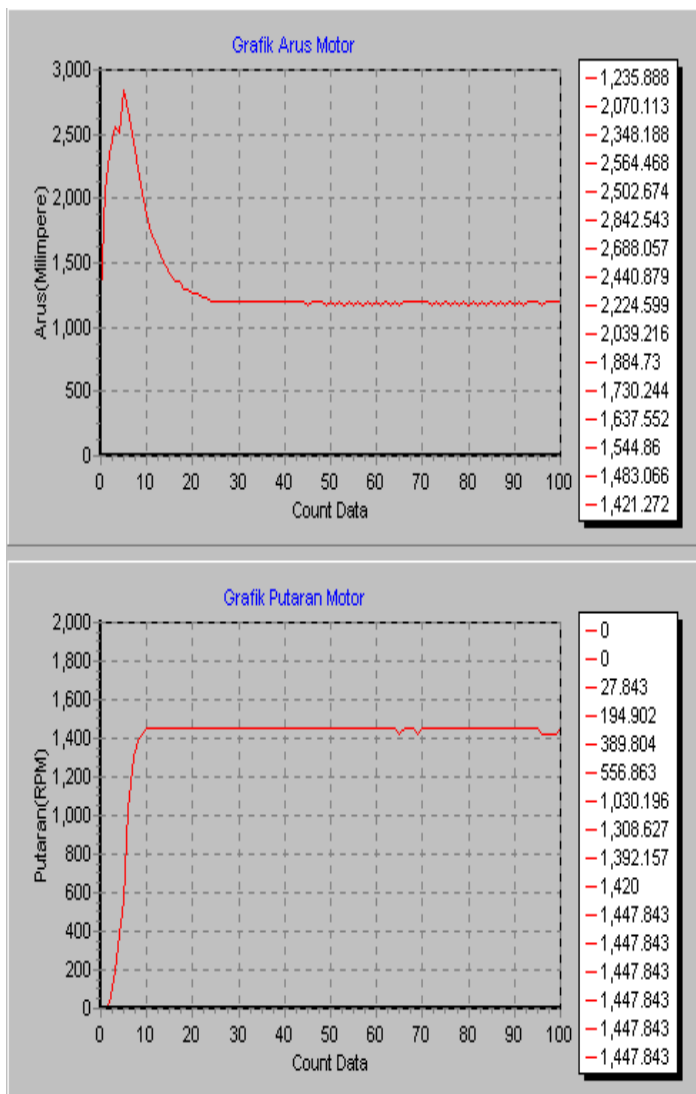

Gambar 8. Karakteristik arus dan putaran dengan setting timer 0,2 detik

Dari karakteristik arus tersebut perpindahan hubungan Y ke $\Delta$ terjadi sebelum arus puncak sehingga arus starting menjadi besar. Setting timer dengan kondisi ini tidak menguntungkan karena konsumsi arus motor besar.

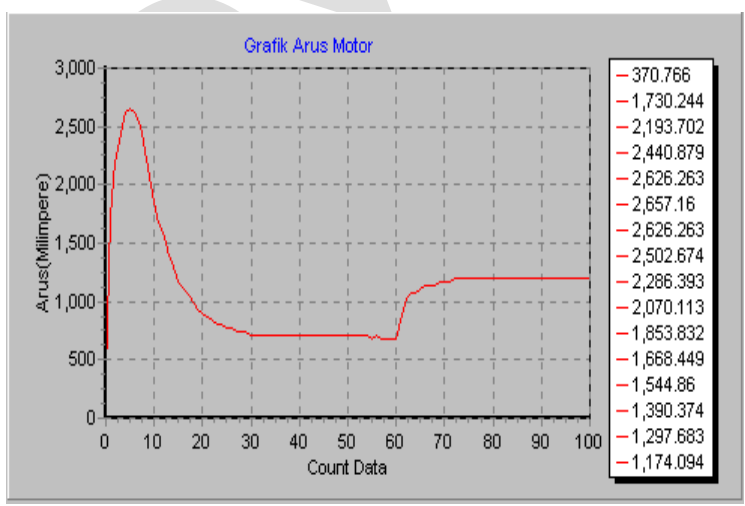

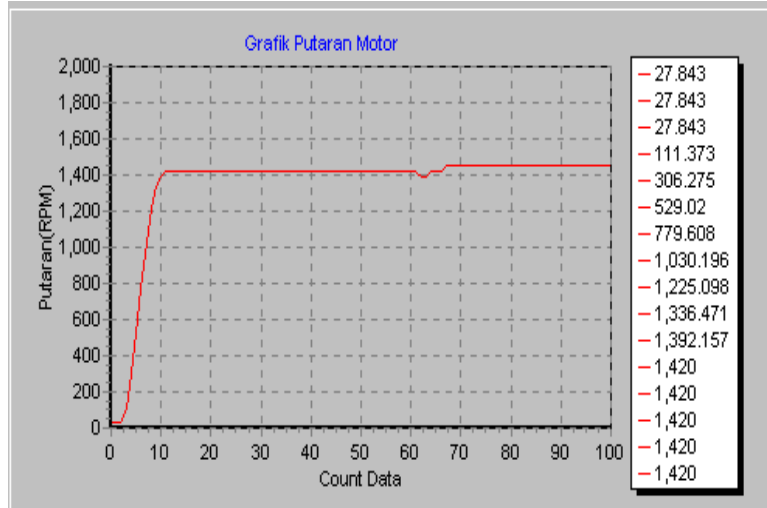

Gambar 9. Karakteristik arus dan putaran dengan setting timer 3 detik

Adapun setting timer perpindahan dari bintang $(\mathrm{Y})$ ke segitiga $(\Delta)$ yang terlalu lama, putaran motor tidak mencapai putaran nominalnya. Hal ini disebabkan karena arus motor rendah pada hubungan bintang (Y).

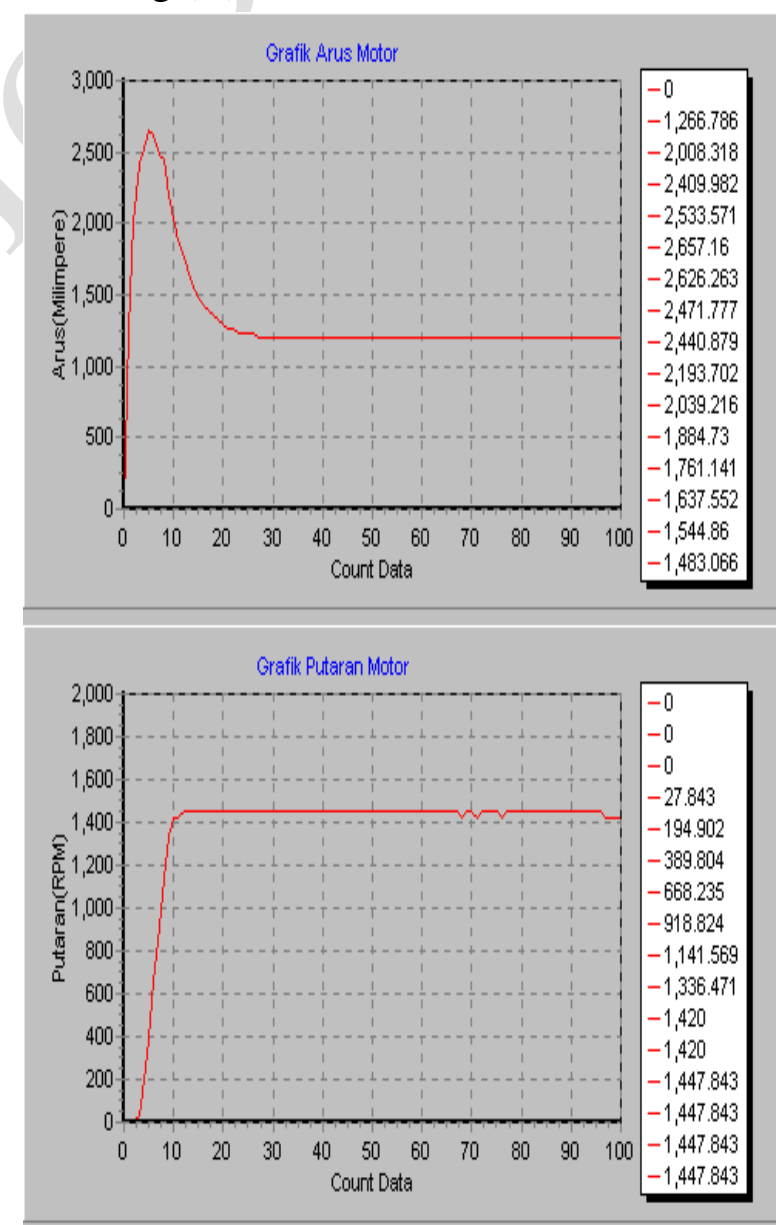

Gambar 10. Karakteristik arus dan putaran dengan setting timer 0,3 detik 


\section{DynamicSainT}

Jilid. V No. 1., April 2020

Pada setting timer perpindahan bintang $(\mathrm{Y})$ ke segitiga $(\Delta)$ yang tepat arus starting motor tidak terlalu besar. Sedangkan putaran motor akan berputar sesuai dengan putaran nominalnya. Dari hasil pengujian setting timer yang tepat untuk jenis motor induksi ini adalah berkisar antara 0,3-0,6 detik.

\section{KESIMPULAN DAN SARAN}

\subsection{Kesimpulan}

Berdasarkan pada uraian-uraian diatas, maka dapat disimpulkan sebagai berikut :

1. Pada sistem pengasutan motor $\mathrm{Y}-\Delta$ membatasi arus starting yang terlalu besar. Putaran nominal motor hanya dapat dicapai saat motor terhubung secara segitiga $(\Delta)$. Sedangkan pada pengasutan sistem Direct On Line (DOL) pada jenis motor induksi dengan spesifikasi :

$$
\begin{array}{ll}
\text { Daya } & : 1,5 \mathrm{Kw} \\
\text { Putaran } & : 1500 \mathrm{rpm} \\
\text { Tegangan } & : 380 / 660 \text { Volt }
\end{array}
$$

memiliki arus starting (2,595 A) lebih rendah dibandingkan dengan arus starting menggunakan sistem Y- $\Delta(2,657$ A pada setting timer 0,3 detik).

2. Setting timer yang tepat pada perpindahan hubungan $\mathrm{Y}$ ke $\Delta$ untuk motor induksi yang memiliki daya 1,5 Kw adalah 0,3 - 0,6 detik. Pada kondisi ini arus starting lebih rendah dan putaran nominal lebih cepat tercapai.

3. Bentuk gelombang arus dan putaran yang dihasilkan pada pengasutan sistem Y- $\Delta$ memiliki karakteristik yang berbeda tergantung setting timer yang diberikan.

\subsection{Saran}

Dari penelitian ini, masih ada beberapa kekurangan yang perlu diperbaiki untuk pengembangan selanjutnya yaitu dari segi software data yang telah direkam tidak dapat didownload ulang. Sehingga data yang telah terekam tidak dapat dilihat kembali meskipun motor sudah tidak berputar lagi.

\section{DAFTAR PUSTAKA}

1. Heriyanto, Agus. 2000. "Rancang Bangun Peralatan Starting Untuk Motor Induksi 3Ф”. Surabaya: Jurusan Teknik Listrik Politeknik Elektronika Negeri Surabaya.

2. http: //www. DataSheetKatalog.com diakses 10 Oktober 2006.

3. Neidle, Michael. 1982. Teknologi Instalasi Listrik. Jakarta: Erlangga.

4. Payung, Zet, dkk. 2006. "Perancangan Alat Penampil Respon Rangkaian Kontrol Berbasis Delphi”. Makassar: Jurusan Teknik Elektro Politeknik Negeri Ujung Pandang.

5. Petruzella, D. Frank. 1996. Elektronik Industri. Yogya: Andi.

6. Sunarto, B. Rumono. 2004. Membangun Sistem Akuisisi Data Berbasis Database Dengan Delphi. Jakarta: Elex Media Komputindo.

7. Supriadi, Muhammad. 2005. Pemrograman IC PPI 8255 Menggunakan Delphi. Yogyakarta: Andi.

8. Sutadi, Dwi. 2004. I/O Bus \& Motherboard. Yogyakarta: Andi.

9. Zuhal. 1991. Dasar Tenaga Listrik. Bandung: ITB. 